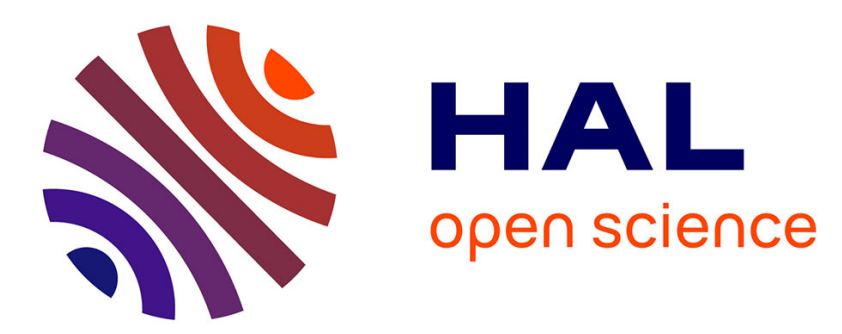

\title{
Agreement between youth-reported and parent-reported psychopathology in a referred sample
}

Harriet Salbach-Andrae, Nora Klinkowski, Klaus Lenz, Ulrike Lehmkuhl

\section{To cite this version:}

Harriet Salbach-Andrae, Nora Klinkowski, Klaus Lenz, Ulrike Lehmkuhl. Agreement between youthreported and parent-reported psychopathology in a referred sample. European Child and Adolescent Psychiatry, 2009, 18 (3), pp.136-143. 10.1007/s00787-008-0710-z . hal-00478069

\section{HAL Id: hal-00478069 \\ https://hal.science/hal-00478069}

Submitted on 30 Apr 2010

HAL is a multi-disciplinary open access archive for the deposit and dissemination of scientific research documents, whether they are published or not. The documents may come from teaching and research institutions in France or abroad, or from public or private research centers.
L'archive ouverte pluridisciplinaire HAL, est destinée au dépôt et à la diffusion de documents scientifiques de niveau recherche, publiés ou non, émanant des établissements d'enseignement et de recherche français ou étrangers, des laboratoires publics ou privés. 
Harriet Salbach-Andrae

Nora Klinkowski

Klaus Lenz

Ulrike Lehmkuhl

\section{Agreement between youth-reported and parent-reported psychopathology in a referred sample}

Received: 12 December 2007

Accepted: 30 May 2008

Published online: 6 January 2009
Dr. H. Salbach-Andrae, PhD ( $\square)$

N. Klinkowski, MD · K. Lenz, MD

U. Lehmkuhl, $\mathrm{PhD}$

Charité-Universitätsmedizin Berlin

Department of Child and Adolescent

Psychiatry

Augustenburger Platz 1

13353 Berlin, Germany

Tel.: +49-30/450566597

Fax: +49-30/450566923

E-Mail: harriet.salbach@charite.de
Abstract Objective The study examined parent-youth agreement regarding reports on psychopathology among adolescents suffering from psychiatric disorders. Method A total of 1,718 patients between the age of 11 and 18, as well as their parents, were assessed using the child behavior checklist (CBCL), and the youth self-report (YSR). Results Poor to low agreement between parent- and adolescent-reported problem behavior on the internalizing scale, the total problem scale and moderate agreement concerning the externalizing scale of the CBCL and the YSR were found. Independent from the amount of psychiatric diagnoses, adolescents reported significantly less behavioral problems than their parents. Concerning externalizing problems, parent-youth disagreement was stronger for patients suffering from comorbid psychiatric disorders, than for adolescents displaying only one psychiatric disorder. Conclusion In clinically referred children, parents are likely to emphasize the severity of the difficulties, whereas adolescents' under-report symptoms.

Key words psychopathology adolescence - agreement child behavior checklist (CBCL) youth self-report (YSR)

\section{Introduction}

There is a strong consensus of opinion that the clinical assessment of children and adolescents' psychopathology requires data from multiple informants [15, 28]. When multiple informants, however, provide information, discrepancies among them are to be expected [20]. Many researchers have reported significant discrepancies between youth-reported and parent-reported psychopathology in children and adolescents [5, 12, 16, 23, 24, 29, 34, 35].

In studies of non clinical samples, youth reported higher severity ratings than their parents or teachers $[2-4,36]$. A few studies involved clinically referred samples and invariantly document a reverse discrep- ancy, where youth ratings of problem severity are lower than parent ratings [27, 31, 37]. In clinically referred children, parents are likely to emphasize the severity of the difficulties which is often likely to result in a ceiling effect, whereas the young persons' ratings are usually correspondingly lower.

Investigations have given most attention to examine how child and adolescent characteristics such as age, gender and problem type are related to informant discrepancies. Concerning age, a meta-analysis showed that agreement between informants' ratings was greater for younger than for older children [5]. The authors interpreted the results in the way that adolescents' behavior may be less observable by informants compared to childrens' behavior. Interestingly, some studies have not detected age differ- 
ences $[14,29,39]$ or figured out that disagreement was higher for younger than for older children [25]. A lot of discrepancies may be attributable to sample characteristics. For example, in Achenbach et al.'s [5] meta-analysis, they categorized child age dichotomously among children and adolescents aged 619 years. In addition, studies that found lower agreement for younger children often have not categorized child age in the same way as Achenbach et al. [5].

Attention has also been given to examine the connection between gender and informants agreement $[21,29,40]$. In sum, the divergent results could be attributable to sample characteristics and in specific populations, gender effects may be occurring.

With regard to SES, various studies have not found a relation between SES and informant discrepancies, when other child and parent characteristics were included [13, 29, 32].

In general, previous studies revealed a higher parent-child agreement regarding externalizing symptoms compared to internalizing symptoms [8, 34]. It has been argued that externalizing problems are more openly observable and directed at others. Internalizing problems, however, are reported more often by children and adolescents themselves and are only poorly recognized by their parents $[10,20,35]$.

Studies revealed that parent-child agreement for the diagnoses of childhood anxiety and depressive disorders showed low to moderate levels of informant agreement $[7,14,15]$. Research has also investigated informant disagreement with regard to specific childhood externalizing problems (aggression, hyperactivity/inattention and oppositional behavior) and revealed low to moderate levels of informant agreement as well $[20,25,26,30]$.

A significant number of studies has shown that many children and adolescents meet the criteria for multiple psychiatric disorders [1]. The discovery that two or even more distinct psychiatric disorders jointly occur in one individual is very important, because psychiatric comorbidity often appears to connote greater impairment and chronicity [6]. Comorbidity often suggests poorer response to treatment and worse longitudinal trajectories [41]. To the best of our knowledge, no study has yet examined, whether parent-youth agreement differs when psychiatric comorbidities are present.

The current study investigates parent-youth agreement regarding psychopathology in youths suffering from different numbers of psychiatric Axis I disorders according to the ICD-10 multi axial classification system. Our referred sample provides statistical power to detect uncommon relationships between youth-reported and parent-reported psychopathology in adolescents.

\section{Method}

\section{Participants}

Four thousand and twenty-two patients ( $>99 \%$ Caucasian) were screened for our chart review study. All of them had been referred to a child and adolescent psychiatry department of a major university hospital in Germany between January 1996 and December 2006. In order to make sure that all patients were able to understand the questions of the child behavior checklist (CBCL), 1,545 patients had to be excluded due to IQ $<85$ or missing IQ data. 116 patients were not included in the study due to ambiguity of diagnoses. Another 843 patients were excluded due to unavailable or missing $\mathrm{CBCL} /$ youth self report (YSR) values ( $>8$ items). Possible criteria for missing data not at random are drop out, deficient German and the presence of psychiatric diagnoses of parents. Thus, the study consisted of 1718 patients ( 963 male) between the age of 11 and 18 (mean age $=13.9, \mathrm{SD}=2.0$ ).

Socioeconomic status (SES) was measured on an eleven-point scale assessing the parents' self-reported occupational status [22]. The scale places each occupation into one of eleven categories $(1=$ unskilled laborer, $6=$ professional employed, $7=$ unskilled self-employed, $11=$ professional self-employed). We distinguished three SES groups: High (groups 5, 6, 10, 11; e.g., manager, physician), middle (groups 3, 4, 9; e.g., electrician, nurse) and low (groups 1, 2, 7, 8; e.g., cashier, textile machine operator). In this study, SES was as follows: High SES (21.0\%), middle SES (67.4\%) and low SES (11.4\%).

All patients were clinically assessed, and bestestimate diagnoses were assigned based on clinical ratings (e.g. CBCL [3] and YSR [4]), clinical observations, and semi-structured interviews with parents and their children ('Basisdokumentation' (BADO); [22]). The BADO is an interview that collects information such as socio-demographic data, psychopathology, past medical history, somatic findings, diagnoses and therapeutic outcome. CBCL and YSR were filled out by parents and adolescents before the semi-structured interviews were accomplished. Thus, both parents and adolescents information were equally incorporated to obtain the clinical diagnoses. Senior board-certified child and adolescent psychiatrists verified all diagnoses in a case conference. For the purposes of this study, patients presenting two or even more distinct Axis I psychiatric disorder according to the ICD-10 multi axial classification system $\left({ }^{* *}\right.$ World Health Organization, 1996) were considered as "comorbid". Participants who had one Axis I psychiatric disorder according to the ICD-10 multi axial classification system were categorized as 
Table 1 Sociodemographic measures

\begin{tabular}{llll}
\hline & $\begin{array}{l}\text { No-disorder } \\
(N=189)\end{array}$ & $\begin{array}{l}\text { One-disorder } \\
(N=938)\end{array}$ & $\begin{array}{l}\text { Comorbid } \\
(N=591)\end{array}$ \\
\hline Admission age & $\begin{array}{l}13.4 \text { year } \\
(S D=1.8)\end{array}$ & $\begin{array}{l}14.0 \text { year } \\
(S D=1.9)\end{array}$ & $\begin{array}{l}13.9 \text { year } \\
(S D=2.1)\end{array}$ \\
$\begin{array}{l}\text { Gender } \\
\text { Male }\end{array}$ & $132(69.8 \%)$ & $476(50.7 \%)$ & $355(60.1 \%)$ \\
$\begin{array}{l}\text { Female } \\
\text { SES }\end{array}$ & $37(30.2 \%)$ & $462(49.3 \%)$ & $236(39.9 \%)$ \\
High & $52(27.0 \%)$ & $199(21.2 \%)$ & $109(18.4 \%)$ \\
Middle & $121(64.0 \%)$ & $639(68.1 \%)$ & $402(68.0 \%)$ \\
Low & $16(8.5 \%)$ & $100(10.7 \%)$ & $80(13.5 \%)$ \\
\hline
\end{tabular}

No-disorder no axis I psychiatric disorder, One-disorder one axis I psychiatric disorder, Comorbid two or more Axis I psychiatric disorder, SD standard deviation, SES socioeconomic status

"one-disorder" and participants with no Axis I psychiatric disorder according to the ICD-10 multi axial classification system were grouped as "no-disorder". Table 1 presents sample characteristics. ICD-10 diagnoses for participants with one or more distinct Axis I psychiatric disorders are displayed in Table 2. The local Ethics Committee considered this chart review to be exempt from review, and written informed consent was not required.

\section{Measures}

\section{Child behavior checklist (CBCL)}

The CBCL parents' form [3] was designed to assess problem behavior in 4-18-year-old sons and daughters. It is one of the most established inventories in both, research and clinical practice with children and adolescents. The German version of the CBCL contains 112 items describing typical behavioral and emotional problems, each to be rated according to a $0-2$ point scale ranging from "not true" (0) to "somewhat or sometimes true" (1) to "very often true or often true" (2). The CBCL yields scores on the following eight syndrome scales: withdrawn, somatic complaints, anxious-depressed, social problems, thought problems, attention problems, delinquent behavior, and aggressive behavior. The total problem scale subsumes the eight syndrome scales. The three syndrome scales withdrawn, somatic complaints and anxious/depressed constitute the broadband internalizing scale. The syndrome scales delinquent behavior and aggressive behavior comprise the broadband externalizing scale. Good reliability and validity of the CBCL were confirmed for the German version $[19,33]$. Raw CBCL scores were transformed to T-scores.

\section{Youth self-report (YSR)}

The YSR [4] was modeled on the CBCL; it measures self-reported ratings of behavioral and emotional
Table 2 Distribution of axis I psychiatric diagnoses in the one-disorder and comorbid group

\begin{tabular}{lcc}
\hline & One-disorder & Comorbid \\
\hline Substance use disorder (F10-F19) & - & 51 \\
Emotional disorder (F32-39, F40-F43, & 548 & 408 \\
$\quad$ F93, F94.0) & 101 & 131 \\
Eating disorders (F50) & - & 41 \\
Personality disorders (F60) & 98 & 197 \\
ADHD (F90)/ADHD + conduct disorder & & \\
$\quad$ (F90.1) & 68 & 208 \\
Conduct disorder (F91, F92) & 123 & 222 \\
Other disorders & & \\
\hline
\end{tabular}

problems. The YSR can be used for ages 11 and up and the items are worded in the first person. It includes 112 items similar to those on the CBCL and provides also scores for the total problem scale: the above-mentioned eight syndrome scales and the internalizing and externalizing broadband scales. Döpfner et al. [18] supported the good reliability and validity scores of the German YSR translation. Raw YSR scores were transformed to T-scores.

\section{Statistical analyses}

Using an analysis of variance and $\chi^{2}$-tests, we analyzed age, SES and gender (Table 1) in relation to the three groups. To assess the clinical significance of between group differences, we evaluated the mean symptom levels of each group using standard cutoffscores for the CBCL and YSR [3, 4]. T-scores above 63 for the two broadband scales as well as the total scale and above 70 for syndrome scales were defined as abnormal. T-scores of 60-63 for the two broadband scales as well as the total problem scale and T-scores of 67-70 for syndrome scales were defined as borderline range. The degree of agreement between parents' and adolescents' ratings on the CBCL and YSR was described using intraclass correlation coefficients (ICC; [11]). Analyses of variance of repeated measures with Bonferroni correction for multiple comparisons were applied to assess differences in average CBCL and YSR total problem scores, externalizing subscores and internalizing subscores for each group (no-disorder, one-disorder, comorbid). Age, SES and gender served as covariates in the statistical analyses to control the influence of possible differences.

\section{Results}

ANOVA reveals that age differs significantly by groups $(\mathrm{F}(2.1716)=7.5, P<0.001$, see Table 1$)$. Scheffé tests showed the no-disorder group to be significantly 
Table 3 Differences in T-scores of the CBCL and YSR between the groups and between informants

\begin{tabular}{|c|c|c|c|c|c|c|}
\hline \multirow[t]{2}{*}{ CBCL/YSR scales } & \multicolumn{2}{|l|}{ No-disorder } & \multicolumn{2}{|l|}{ One-disorder } & \multicolumn{2}{|l|}{ Comorbid } \\
\hline & CBCL mean (SD) & YSR mean (SD) & $\mathrm{CBCL}$ mean $(\mathrm{SD})$ & YSR mean (SD) & CBCL Mean (SD) & YSR mean (SD) \\
\hline Total problem scale & $55.7(11.8)$ & $46.5(9.3)$ & $61.3(9.6)$ & $52.7(10.3)$ & $66.5(9.1)$ & $56.9(10.4)$ \\
\hline \multicolumn{7}{|l|}{ Scales } \\
\hline Internalizing & $56.1(11.4)$ & $47.3(9.6)$ & $61.9(10.5)$ & $53.5(11.5)$ & $64.9(10.6)$ & $55.9(11.5)$ \\
\hline Externalizing & $52.1(12.2)$ & $47.5(9.8)$ & $56.7(11.3)$ & $51.9(10.7)$ & $63.2(11.6)$ & 57.1 (11.2) \\
\hline \multicolumn{7}{|l|}{ Syndrome scales } \\
\hline Withdrawn & $57.5(8.8)$ & $52.5(5.4)$ & $62.1(10.5)$ & $56.0(8.6)$ & $63.7(10.2)$ & $56.5(8.5)$ \\
\hline Somatic compl. & $58.7(8.1)$ & $54.0(5.4)$ & $60.7(9.3)$ & $55.8(7.2)$ & $62.3(9.9)$ & $57.5(8.3)$ \\
\hline Anxious-depr. & $57.4(7.9)$ & $52.7(5.1)$ & $61.4(9.4)$ & $56.9(8.7)$ & $64.5(10.1)$ & $58.8(9.4)$ \\
\hline Social problems & $56.7(8.4)$ & $53.5(6.1)$ & $58.6(8.9)$ & $55.5(7.9)$ & $61.7(10.5)$ & $57.2(8.8)$ \\
\hline Thought probl. & $56.0(7.5)$ & $51.0(3.5)$ & $59.3(9.0)$ & $53.0(5.6)$ & $60.9(9.7)$ & $54.2(7.3)$ \\
\hline Attention probl. & $60.8(10.2)$ & $54.6(6.6)$ & $61.7(9.4)$ & $56.8(8.3)$ & $65.0(9.6)$ & $59.6(9.4)$ \\
\hline Delinquent beh. & $55.6(7.5)$ & $53.8(5.9)$ & $59.3(9.3)$ & $56.9(7.9)$ & $64.2(9.9)$ & $60.2(9.1)$ \\
\hline Aggressive beh. & $56.1(9.0)$ & $52.3(5.2)$ & $57.9(9.1)$ & $54.4(6.9)$ & $63.8(11.2)$ & $57.8(8.7)$ \\
\hline
\end{tabular}

No-disorder no Axis I psychiatric disorder, One-disorder one Axis I psychiatric disorder, Comorbid two or more axis I psychiatric disorder, CBCL child behavior checklist, $Y S R$ youth self-report, SD standard deviation

younger than the one-disorder and the comorbid group. Younger patients did not differ significantly from older patients according to the number of in- and outpatient psychiatric treatments $\left(\chi^{2}(\mathrm{df}=1)=2.4\right.$, $P<0.12$ ). There were statistically significant group differences based on SES $\left(\chi^{2}(\mathrm{df}=4)=10.3\right.$, $P<0.05)$ and gender $\left(\chi^{2}(\mathrm{df}=2)=29.2, P<0.001\right.$; see Table 1).

Table 3 presents the means and standard deviations for the entire sample. In sum, CBCL mean scores were globally higher than YSR mean scores. For the comorbid-group, parent-reported problems were within the abnormal range on the total problem scale, the internalizing scale and within the borderline range on the externalizing scale of the CBCL. Parent-reported problems for the one-disorder group were within the borderline range on the total problem scale and the internalizing scale of the CBCL. All other parent-reported problems and all self-reported problems (YSR) were rated within normal range. As expected, numerous syndrome scales were not within the borderline or abnormal range. Therefore, we only included the total problem scale, the internalizing, and the externalizing scale in the following statistical analyses.

Table 4 provides ICC for CBCL and YSR, for total problems, for externalizing and internalizing scales, separately for the three groups (no-disorder, onedisorder, comorbid). Comparing CBCL and YSR total scores as well as internalizing and externalizing scales, the ICC ranged from 0.16 (total problem score for the comorbid group) to 0.51 (externalizing scale for the no-disorder group).

ANOVA of repeated measures with Bonferroni correction for multiple comparisons $(0.05 / 2=0.025)$ were used to examine the differences in mean scores between informants, and between the three groups. The effect of the informant was significant on the total problem scale $(F(1.1717)=199.6, P<0.001)$, the internalizing scale $(F(1.1717)=139.2, P<0.001)$ and the externalizing scale $(F(1.1717)=166.2, P<0.001)$. This reveals that parents reported significantly more problems than adolescents (see Table 2). Additionally, the group effect was also significant on the total problem scale $(F(2.1716)=123.1, \quad P<0.001)$, the internalizing scale $(F(2.1716)=59.8, P<0.001)$ and the externalizing scale $(F(2.1716)=101.8, P<0.001)$. Patients with comorbid disorders had the highest scores and adolescents displaying no psychiatric disorder had the lowest scores on all scales (see Table 2). The interaction between informants and groups was significant on the externalizing scale $(F(2.1716)=4.4$, $P<0.01)$. Paired $t$ tests were used for post-hoc comparisons; they displayed the highest discrepancies between CBCL and YSR for the comorbid group, followed by the one-disorder group. The no-disorder

Table 4 Parent-adolescent agreement on the CBCL and the YSR

\begin{tabular}{llll}
\hline CBCL/YSR scales & $\mathrm{ICC}$ & & \\
\cline { 2 - 4 } & $\begin{array}{l}\text { Comorbid } \\
(N=591)\end{array}$ & $\begin{array}{l}\text { One-disorder } \\
(N=938)\end{array}$ & $\begin{array}{l}\text { No-disorder } \\
(N=189)\end{array}$ \\
\hline $\begin{array}{l}\text { Total problem scale } \\
\begin{array}{l}\text { Scales } \\
\text { Internalizing } \\
\text { Externalizing }\end{array}\end{array}$ & 0.16 & 0.19 & 0.26 \\
\hline
\end{tabular}

Agreement on total, internalizing and externalizing scales using ICC $C B C L$ child behavior checklist, YSR youth self-report, ICC intraclass coefficient, No-disorder no axis I psychiatric disorder, One-disorder one axis I psychiatric disorder, Comorbid two or more axis I psychiatric disorder agreements: $>0.8=$ almost perfect, $\quad 0.6-0.8=$ substantial, $\quad 0.4-0.6=$ moderate, $0.2-$ $0.4=$ low, $0.2<$ poor 
group demonstrated fewest discrepancies between CBCL and YSR (see Table 4). No significant interaction was found for the total problem scale $(F(2$, $1716)=1.2, P<0.30)$ and the internalizing scale $(F(2.1716)=0.5, P=0.58)$. The interaction between informants and gender was significant for the total problem scale $(F(2.1716)=62.1, \quad P<0.001)$, the externalizing scale $(F(2.1716)=55.0, P=0.001)$ and the internalizing scale $(F(2.1716)=42.8, P=0.001)$. Post-hoc paired t-tests demonstrated the highest discrepancies between CBCL and YSR for males compared to females on the total problem scale, the internalizing and the externalizing scale (see Table 5). Furthermore, the interaction between informants and age was significant on all three scales (total problem scale: $F(2.1716)=54.3, P=0.001$; externalizing scale: $F(2.1716)=68.4, \quad P=0.001 ; \quad$ internalizing scale: $F(2.1716)=34.7, P=0.001)$. Paired $t$ tests displayed higher discrepancies between CBCL and YSR for younger (11-14 years) patients than for older patients (15-18 years) on all three scales (total problem scale, internalizing and the externalizing scale; see Table 5). No significant interaction was found between informant and SES.

\section{Discussion}

The objective of the present study was to assess parent-youth agreement regarding the psychopathology in a referred adolescent sample and to examine whether there are any discrepancies between patients suffering from no psychiatric disorder, one psychiatric disorder or more than one psychiatric disorder.

With regard to all three groups (no-disorder, onedisorder, comorbid), results show poor to low agreement between parent- and youth-reported problem behavior on the internalizing scale and on the total problem scale of the CBCL and the YSR. In contrast, parent-youth concordance concerning the externalizing scale of the CBCL and YSR revealed moderate agreement. These findings are consistent with previous studies comparing parent reports and youth self-reports of adolescent emotional and behavioral problems $[5,12,23,43]$. In line with existing research, the level of parent-adolescent concordance was higher for the externalizing scale than for the internalizing scale $[8$, 34]. This could be due to the fact that internalizing problems are less observable.

Our results reveal that adolescents reported significantly lower scores on the total problem scale, on all broadband scales and syndrome scales than their parents. Those findings contrast other studies, which showed that adolescents reported more internalizing 
and externalizing problem behavior than their parents $[34,35]$. Sample characteristics might be able to explain the differences between our study and previous ones. Most of the earlier studies assessed parentyouth agreement among the general population [12, 24, 35]. For example, Phares and Danforth [31] assessed adolescent and adult reports of distress over clinically referred adolescents' problems and found that parents were more bothered by both, internalizing and externalizing behaviors than adolescents. It could be possible that the referral may have influenced the pattern of parent-youth (dis)-agreement. Parental impression of problems that cause significant distress would be more important in obtaining a referral to a university mental health clinic rather than the adolescents' own perceptions of problems. Furthermore, the observed discrepancies might be denial of illness or lack of insight on the part of the adolescents.

It is remarkable that the syndrome scales in our sample do not reach borderline or even abnormal range. Possible underlying reason might be that the patients in our sample suffered from different types of psychiatric disorders. Hence, those patients score differently on particular syndrome scales and, thus, lower scores on the syndrome scales were achieved.

The groups differ significantly in the amount of CBCL and YSR scores. Patients suffering from comorbid disorders displayed the highest scores on the total problem score, as well as on the externalizing and internalizing scales. Patients displaying one Axis I psychiatric disorder scored higher on the total problem score and the internalizing and externalizing scale in comparison to patients displaying no psychiatric Axis I disorder. These findings strengthen the assumption that comorbidity is associated with higher levels of symptom severity. Higher levels of symptom severity often signals poorer response to treatment and worse longitudinal trajectories $[9,42]$. Thus, the development of better focused treatments and prevention programs for comorbid disorders are necessary.

Moreover, our results reveal that the number of psychiatric diagnoses has an impact on the amount of parent-adolescent discrepancy concerning the externalizing scale of the CBCL / YSR. With regard to informants' ratings of externalizing problems, parentyouth disagreement was the strongest for adolescents suffering from comorbid disorders, followed by the one-disorder group. Surprisingly, the three groups did not differ in parent-youth disagreement relating to the total problem scale and the internalizing scale of the CBCL/YSR. One possible explanation for the findings could be that internalizing problems are less observable and greater parent-child-disagreement exists independently from the number of psychiatric diagnoses. Informant discrepancy concerning externalizing problems increases in terms of the number of diagnoses of the child or adolescent. Possible reasons for these findings might be stronger denial of illness or the lack of insight for patients displaying comorbid psychiatric disorders.

In our study age and gender differed significantly between groups. One possible explanation for this result could be that in late childhood boys display more psychiatric disorders, whereas in adolescence girls show more psychiatric disorders. The reason why SES differed significantly between the three groups could be that psychiatric disorders are more often found in lower than in upper social class groups.

Besides, our results show that disagreement between informants' ratings was greater for younger children than for adolescents. This finding contrasts many studies which reported higher agreement between informants for younger than for older children $[5,14,21,29,39]$. This discrepancy might be due to sample characteristics. For example, in Achenbach et al.'s [5] meta-analysis, 269 samples in 119 studies were investigated and child age was categorized dichotomously among children and adolescents aged 6-19 years. In our study, participants were between 11 and 18 years.

Regarding gender differences, discrepancy between informants' ratings was greater for males compared to females. Thus, it might be possible that in clinical samples aged 11-18 years gender differences occur [17]. Future research should focus on specific populations, when relations between child gender and informant discrepancies are assessed.

With regard to SES and informant discrepancies our results showed no significant relation. This result stays in line with many previously cited studies that did not find a connection between SES and informant discrepancies [13, 29, 38].

\section{Limitations}

First, age, SES and gender differed significantly by diagnoses. However, since these variables served as covariates in the statistical analyses, they cannot be taken into account for the differences found in this study. A second limitation may be a referral bias, because the adolescents were referred to a child and adolescent psychiatric clinic at a university hospital. Nearly one third of the children referred to this department displayed two or even more distinct Axis I psychiatric disorders. Therefore, the findings probably cannot be generalized to other mental health settings. Thirdly, although the diagnoses were based on vastly structured multi-informant data with 
case conferences, and even if best-estimate diagnoses were given under the guidance of experienced broadly certified child and adolescent psychiatrists, we did not include an internationally accepted semistructured interview, which may have further strengthened the diagnostic classification. Because CBCL and YSR have an impact on the best-estimate diagnoses, it could be possible that some diagnoses were unreliable due to high parent-child disagreement according to CBCL and YSR. However, the parents and adolescents perspectives were valid in their own right and included in the diagnostic process. Fourthly, from the current results it cannot be inferred, which informant was "correct" regarding the discrepancies. Future studies should include a third informant, such as a teacher interacting with the adolescent at school. In the light of the clear advantage of investigating such a large group of referred adolescents, however, these limitations appear to be of minor importance.

\section{Conclusion}

In summary, agreement between youth-reported and parent-reported psychopathology in this large referred sample was poor to moderate. Our evidence reveals that, independent from the amount of psychiatric diagnoses, adolescents in a clinical setting reported significantly less behavioral problems than their parents. It can be assumed that the referral has influenced the result. In clinically referred children, parents are likely to emphasize the severity of the difficulties, whereas adolescents' score lower. Moreover, denial of illness or the lack of insight on the part of the youths might as well be responsible for the observed discrepancies. Concerning externalizing problems, parent-youth-discrepancies were stronger for patients suffering from comorbid disorders, than for adolescents displaying one psychiatric Axis I disorder respectively for adolescents displaying no psychiatric disorders.

\section{References}

1. Achenbach TM (1995) Diagnosis, assessment, and comorbidity in psychosocial treatment research. J Abnorm Child Psychol 23:45-65

2. Achenbach TM (1991a) Integrative guide for the $1991 \mathrm{CBCL} / 4-18$, YSR and TRF profiles. University of Vermont, Department of Psychiatry, Burlington

3. Achenbach TM (1991b) Manual for the child behavior checklist/4-18 and 1991 profile. University of Vermont, Department of Psychiatry, Burlington

4. Achenbach TM (1991c) Manual for the youth self report form and 1991 profile. University of Vermont, Department of Psychiatry, Burlington

5. Achenbach TM, McConaughy SH, Howell CT (1987) Child/adolescent behavioral and emotional problems: implications of cross-informant correlations for situational specificity. Psychol Bull 101:213-232

6. Angold A, Costello EJ, Erkanli A (1999) Comorbidity. J Child Psychol Psychiatry 40:57-87

7. Angold A, Weissman MM, John K, Merikangas KR, Prusoff BA, Wickramaratne $\mathrm{P}$, Gammon GD, Warner V (1987) Parent and child reports of depressive symptoms in children at low and high risk of depression. J Child Psychol Psychiatry 28:901-915

8. Berg-Nielsen TS, Vika A, Dahl AA (2003) When adolescents disagree with their mothers: CBCL-YSR discrepancies related to maternal depression and adolescent self-esteem. Child Care Health Dev 29:207-213
9. Beyers JML, R (2003) Developmental aspects of delinquency and co-occuring aggression and depressed mood in male adolescents. J Abnorm Child Psychol 31:247-266

10. Bird HR, Gould MS, Staghezza B (1992) Aggregating data from multiple informants in child psychiatry epidemiological research. J Am Acad Child Adolesc Psychiatry 31:78-85

11. Bland JM, Altman DG (1986) Statistical methods for assessing agreement between two methods of clinical measurement. Lancet 1:307-310

12. Cantwell DP, Lewinsohn PM, Rohde P, Seeley JR (1997) Correspondence between adolescent report and parent report of psychiatric diagnostic data. J Am Acad Child Adolesc Psychiatry 36:610-619

13. Chi TC, Hinshaw SP (2002) Motherchild relationships of children with ADHD: the role of maternal depressive symptoms and depression-related distortions. J Abnorm Child Psychol 30:387-400

14. Choudhury MS, Pimentel SS, Kendall PC (2003) Childhood anxiety disorders: parent-child (dis)agreement using a structured interview for the DSM-IV. J Am Acad Child Adolesc Psychiatry 42:957-964

15. Comer JS, Kendall PC (2004) A symptom-level examination of parent-child agreement in the diagnosis of anxious youths. J Am Acad Child Adolesc Psychiatry 43:878-886
16. Crystal DS, Ostrander R, Chen RS, August GJ (2001) Multimethod assessment of psychopathology among DSMIV subtypes of children with attentiondeficit/hyperactivity disorder: self-, parent, and teacher reports. J Abnorm Child Psychol 29:189-205

17. De Los Reyes A, Kazdin AE (2005) Informant discrepancies in the assessment of childhood psychopathology: a critical review, theoretical framework, and recommendations for further study. Psychol Bull 131:483-509

18. Doepfner M, Berner W., Lehmkuhl G (1995) Reliabilität und faktorielle Validität des youth self-reports. Diagnostica 41:221-244

19. Dopfner M, Schmeck K, Berner W, Lehmkuhl G, Poustka F (1994) Reliability and factorial validity of the child behavior checklist-an analysis of a clinical and field sample]. Z Kinder Jugendpsychiatr 22:189-205

20. Edelbrock C, Costello AJ, Dulcan MK, Conover NC, Kala R (1986) Parentchild agreement on child psychiatric symptoms assessed via structured interview. J Child Psychol Psychiatry 27:181-190

21. Engel NA, Rodrigue JR, Geffken GR (1994) Parent-child agreement on ratings of anxiety in children. Psychol Rep 75:1251-1260

22. Englert E, Poustka F (1995) Das Frankfurter Kinder- und Jugendpsychiatrische Dokumentationssystem. Prax Kinderpsychol Kinderpsychiat 44:158-167 
23. Ferdinand RF, van der Ende J, Verhulst FC (2004) Parent-adolescent disagreement regarding psychopathology in adolescents from the general population as a risk factor for adverse outcome. J Abnorm Psychol 113:198-206

24. Ferdinand RF, van der Ende J, Verhulst FC (2006) Prognostic value of parentadolescent disagreement in a referred sample. Eur Child Adolesc Psychiatry 15:156-162

25. Grills AE, Ollendick TH (2003) Multiple informant agreement and the anxiety disorders interview schedule for parents and children. J Am Acad Child Adolesc Psychiatry 42:30-40

26. Jensen PS, Rubio-Stipec M, Canino G, Bird HR, Dulcan MK, Schwab-Stone ME, Lahey BB (1999) Parent and child contributions to diagnosis of mental disorder: are both informants always necessary? J Am Acad Child Adolesc Psychiatry 38:1569-1579

27. Kazdin AE, French NH, Unis AS (1983) Child, mother, and father evaluations of depression in psychiatric inpatient children. J Abnorm Child Psychol 11:167-179

28. Kendall PC, Flannery-Schroeder EC (1998) Methodological issues in treatment research for anxiety disorders in youth. J Abnorm Child Psychol 26:2738

29. Kolko DJ, Kazdin AE (1993) Emotional/behavioral problems in clinic and nonclinic children: correspondence among child, parent and teacher reports. J Child Psychol Psychiatry 34:991-1006
30. MacLeod RJ, McNamee JE, Boyle MH, Offord DR, Friedrich M (1999) Identification of childhood psychiatric disorder by informant: comparisons of clinic and community samples. Can J Psychiatry 44:144-150

31. Phares V, Danforth JS (1994) Adolescents', parents', and teachers' distress over adolescents' behavior. J Abnorm Child Psychol 22:721-732

32. Ritsher JE, Warner V, Johnson JG, Dohrenwend BP (2001) Inter-generational longitudinal study of social class and depression: a test of social causation and social selection models. Br J Psychiatry Suppl 40:s84-s90

33. Schmeck K, Poustka F, Dopfner M, Pluck J, Berner W, Lehmkuhl G, Fegert JM, Lenz K, Huss M, Lehmkuhl U (2001) Discriminant validity of the child behaviour checklist CBCL-4/18 in German samples. Eur Child Adolesc Psychiatry 10:240-247

34. Seiffge-Krenke I, Kollmar F (1998) Discrepancies between mothers' and fathers' perceptions of sons' and daughters' problem behaviour: a longitudinal analysis of parent-adolescent agreement on internalising and externalising problem behaviour. J Child Psychol Psychiatry 39:687-697

35. Sourander A, Helstela L, Helenius H (1999) Parent-adolescent agreement on emotional and behavioral problems. Soc Psychiatry Psychiatr Epidemiol 34:657-663

36. Stanger C, Achenbach TM, McConaughy SH (1993) Three-year course of behavioral/emotional problems in a national sample of 4- to 16-year-olds: 3 . Predictors of signs of disturbance. J Consult Clin Psychol 61:839-848
37. Thurber S, Osborn RA (1993) Comparisons of parent and adolescent perspectives on deviance. J Genet Psychol 154:25-32

38. Treutler CM, Epkins CC (2003) Are discrepancies among child, mother, and father reports on children's behavior related to parents' psychological symptoms and aspects of parent-child relationships? J Abnorm Child Psychol 31:13-27

39. Verhulst FC, Althaus M, Berden GF (1987) The child assessment schedule: parent-child agreement and validity measures. J Child Psychol Psychiatry 28:455-466

40. Verhulst FC, van der Ende J (1992) Agreement between parents' reports and adolescents' self-reports of problem behavior. J Child Psychol Psychiatry 33:1011-1023

41. Weiss B, Susser K, Catron T (1998) Common and specific features of childhood psychopathology. J Abnorm Psychol 107:118-127

42. Wilk JE, West JC, Narrow WE, Marcus S, Rubio-Stipec M, Rae DS, Pincus HA, Regier DA (2006) Comorbidity patterns in routine psychiatric practice: is there evidence of underdetection and underdiagnosis? Compr Psychiatry 47:258-264

43. Yeh M, Weisz JR (2001) Why are we here at the clinic? Parent-child (dis)agreement on referral problems at outpatient treatment entry. J Consult Clin Psychol 69:1018-1025 